\title{
Dynamics of configuring and interpreting the disaster risk script: Experiences from Zimbabwe
}

\author{
Authors: \\ Pathias P. Bongo ${ }^{1}$ \\ Paul Chipangura ${ }^{1}$ \\ Mkhokheli Sithole \\ Funa Moyo ${ }^{1}$ \\ Affiliations: \\ ${ }^{1}$ Institute of Development \\ Studies, National University \\ of Science and Technology, \\ Zimbabwe \\ Correspondence to: \\ Pathias Bongo \\ Email: \\ paradzayib@gmail.com \\ Postal address: \\ Institute of Development \\ Studies, National University \\ of Science and Technology, \\ 38 Duncan Road, Suburbs, \\ Bulawayo, Zimbabwe

\section{Dates:} \\ Received: 16 Aug. 2012 \\ Accepted: 18 Apr. 2013 \\ Published: 12 Aug. 2013

\section{Keywords:} \\ Disasters; experiences; \\ interpreting; perceptions \\ script; risk \\ How to cite this article: \\ Bongo, P.P., Chipangura, P., \\ Sithole, M. \& Moyo, F., 2013 \\ 'Dynamics of configuring \\ and interpreting the disaster \\ risk script: Experiences from \\ Zimbabwe', Jàmbá: Journal \\ of Disaster Risk Studies 5(2), \\ Art. \#93, 11 pages. \\ http://dx.doi.org/10.4102/ \\ jamba.v5i2.93

\section{Note:} \\ 1st Biennial Conference, \\ Southern African Society for \\ Disaster Reduction (SASDiR), \\ 09 to 11 October 2012, \\ Potchefstroom, South Africa.

\section{Copyright:} \\ C 2013. The Authors. \\ Licensee: AOSIS \\ OpenJournals. This work \\ is licensed under the \\ Creative Commons \\ Attribution License.

\section{Read online:}

People in Zimbabwe have been faced with disasters in different forms and at various levels. When people experience hazard events and disasters, they perceive these phenomena through lenses that are largely shaped by their local day-to-day experiences and some external influence. As they do this, they develop their own local conception of hazards and disasters, and they tend to model their response or preparedness through this. This article argues that on the basis of this premise, each society therefore develops its own unique and localised way of interpreting the disaster, which comes in the form of a 'script', that needs to be deciphered, read, analysed and understood within local priorities and knowledge systems. The hazard may be the same, say, fire, but as it occurs in different communities, they configure and read the fire script differently, hence spawning different response and prevention strategies. The way people anticipate, prepare for, and respond to a particular disaster stems from their perception of it, based on their own local conceptions of reality. The article argues that effective disaster risk reduction must focus on people's holistic understanding of the unfolding scenario, thereby feeding into disaster risk early warning systems. For effective understanding of the utility of early warning systems, the socio-cultural processes involved in the ideation of the disaster cannot be ignored. It is also critical to examine people's past experiences with external early warning systems, and how much faith they put in them.

\section{Introduction}

A major livelihood disrupting development has been the increase in intensity and frequency of natural shocks and stresses as a result of climate change. The United Nations Office for Disaster Risk Reduction (UNISDR) and the Centre for Research on Epidemiology of Disasters (CRED) revealed that in 2011, 302 human impact disasters claimed 29782 lives, affected 206 million, and inflicted record economic damage of $\$ 366$ billion (KUNA 2011). The rain-fed agro base of most Southern African economies, including Zimbabwe, has made these countries particularly vulnerable to climatic extremes, jerking people from their seasoned livelihood modes. The effects of climate change and man-made hazards in such contexts are giving rise to largely negative consequences in vulnerability issues, triggering livelihood complexities as they intersect with issues that include legislation, policy, institutions and socio-economic environment. A study conducted by the Earth Institute at Columbia University (USA) to assess the effect of natural disasters as well as risks to human populations and economic activity shows that drought and combinations of drought and hydro-meteorological hazards are the main causes of mortality and economic losses in sub-Saharan Africa (Dilley et al. 2005). The principal risks can be divided into those that threaten life directly, such as floods and earthquakes, and those that threaten living conditions through their potential effect on the environment, such as soil erosion and landslides, or on the food chain, such as epizootics and epiphytotics (Frazier 1999, quoted in Alexander 2006:5). In both cases, it is difficult to predict future mortality, as changes in society, demography and development continually alter vulnerability, whilst hazards include both rare events that are not frequent enough to provide clear trends and climate changes whose implications have not yet fully revealed themselves (Adger \& Brooks 2003, quoted in Alexander 2006:5).

Humanity has long sought to explain disasters, often invoking deities, bad luck, or nature's anger as the explanation. When modern Western science started tackling the challenge of disasters, much blame was attributed to environmental hazards causing disasters, often because individuals allegedly had poor perception of disaster risk or lacked the interest to deal with the hazards. Disaster risk was often identified predominantly with hazard, focusing primarily on nature's behaviour. This view implied solutions that involved society controlling and dominating nature in order to protect people from nature's wrath. The debate was framed as a battle or war of humanity against the elements (Kelman 2011:2). In tackling disasters, the focus is frequently on an environmental event, such as a tornado or earthquake, which is often termed the hazard. These environmental events are normal and they serve important ecological and societal functions. 
Examples are a flood fertilising land and providing water resources or a windstorm knocking down old trees to provide habitats on the forest floor along with space for new trees to grow. Such events can be termed hazards from a human perspective when humans identify the potential for society to be harmed by those events.

\section{The disaster risk script}

For Anderson (2011:3), disasters indicate the surpassing of thresholds of acceptable or foreseeable social and economic losses. What constitutes those thresholds varies widely, however, leading to a situation in which the definition of disaster depends almost solely on the individual or collective 'eye of the beholder'. Until experience strikes, at least, disasters are open signifiers, to be moulded to the parameters of those who use the term. This abstractness makes disaster highly useful in political discourse, as political actors easily put definitions of disaster to work in the task of forging or de-authorising political platforms and ideologies. Barton (2005) regards a disaster as a form of 'collective stress', a crisis with a bad ending. Whilst acknowledging the existence of many definitions of a disaster, this article is not primarily concerned with a precise or 'ideal' definition, but on how it is characterised as society attempts to understand this phenomenon. Here reference is made to the people affected by the disaster (directly and indirectly), observers, policy makers, political leaders, disaster and development practitioners, researchers and academics, amongst others. What causes a disaster may well have an impact on the manner in which it is experienced. However, perceptions regarding causation are shaped by a cultural script that seeks to endow events, especially extreme ones, with meaning. So, in the 19th century, many so-called technologically 'caused' disasters were interpreted as a manifestation of God's anger toward human arrogance. In such instances, anxiety about the consequences of technological change encouraged the perception that ultimately a disaster was caused by an 'Act of God'. Today, such events would be associated with human action and the cause would be perceived as that of human irresponsibility or malevolence. For most people, the really important question is not how but why a disaster occurred. It is through people's search for meaning that the answer to this question is constructed (Furedi 2007:484). Whatever causal effect one assigns to specific disaster agents, their human impact is mediated through a community's system of culture.

Borrowing from environmental sociologists, the real environment is seen through a cultural filter, made up of attitudes, limits set by observation techniques, and past experience. By studying the filter and reconstructing the perceived environment, the observer is able to explain particular options and actions on the part of the group being studied. Before the modern period, the lenses in the cultural filter were composed of religious myths and teachings. Real and perceived environments differ. The latter is the important influence on decision making. Environmental perceptions are different in different cultures and this reflects cultural differences. The same can arguably be said to hold true for disasters. This does not mean that a disaster is a phenomenon that cannot manifest objectively across cultures and contexts. Rather, it is the meaning and interpretation of the phenomenon that matters, and this is the crux of this article. A flood can have the same physical characteristics across cultures, but how people 'read its script' and what it holds in store for them, their livelihoods and environment is a critical determinant of how they in turn anticipate, cope with, and respond to it.

In many parts of Zimbabwe, the disaster risk script has been dominated by HIV and AIDS, drought, floods, road traffic accidents, zoonoses, cholera, typhoid and veld fires. Jonsson, Madelene and Sapir (2009:6) provide a tabular presentation of what they consider to be the three major disasters in Zimbabwe and their impacts (Table 1).

\section{Research methodology}

This research used a mixture of both primary and secondary sources of data to gain an impression of how people developed the disaster risk script, and how such development influenced their interpretation and understanding of the disaster script. The research was largely a survey. The field work was limited to selected people from Plumtree, Matobo, Chirumanzu, Shamva and Gwanda districts, as well as Harare. People interviewed included Rural District Council (RDC) employees in the four districts mentioned above, community members who had been trained in disaster risk reduction (DRR) and livelihoods by some non-

TABLE 1: The three major disasters in Zimbabwe.

\begin{tabular}{llll}
\hline Type of disaster & Time & Number of people affected & Affected areas of the country \\
\hline Drought & $1982-1984$ & 700000 & Central, southern, eastern and western parts \\
& $1991-1995$ & 5000000 & - \\
& 1998 & 55000 & Matabeleland South \\
& $2001-2003$ & 6000000 & Midlands, Matabeleland North and South, Masvingo, Manicaland, Mashonaland Central and West \\
Flood & $2007-2008$ & 2100000 & Masvingo, Matabeleland North and South, Midlands, Manicaland, Mashonaland Central, East and West \\
& 1998 & - & Southern part \\
& 2000 & 266000 & Manicaland, Masvingo, Matabeleland South, Midlands \\
& 2001 & 30000 & Mashonaland Central, Matabeleland North \\
& 2003 & 18000 & Mashonaland Central and West \\
Tropical cyclone & 2007 & 15000 & Mashonaland Central \\
& $2007-2008$ & 2000 & Masvingo \\
\hline
\end{tabular}


governmental organisations (NGOs), district-level heads of government departments who participated in drafting district disaster management plans for the three districts and two urban centres, lecturers and researchers in disasters from the Institute of Development Studies at the National University of Science and Technology (IDS-NUST), Diploma and Masters in Disaster Management students studying at IDS-NUST and people not involved in disaster issues. In the survey, a total of 100 questionnaires were distributed to the categories of people indicated above.

\section{Sampling techniques}

The study used the non-probability purposive and convenience sampling methods, where the idea was to target specific people ranging from opinion leaders to the poorest of the poor in the rural areas. The idea was to target people who were directly involved in disaster and development issues at various levels, so as to elicit their views on disasters and their characterisation. A small portion of the sample comprised people who did not have prior formal involvement in disaster issues. With these participants, researchers sought to understand the mindsets of the 'common' person on disasters and their interpretation. The understanding of the researchers was that disasters usually happen in a context dominated by these common people, in the sense of their not being formally involved in disaster issues. The survey did not make use of focus group discussions (FDGs). It was felt that data sources from secondary sources and impressions gained by the authors during general interaction with community members, disaster specialists and RDC employees in DRR work would be used to replace FGDs. In addition, the authors had already in 2010 conducted some FGDs on disasters with community members in Bulilima, Gwanda and Mangwe districts. Records of these FGDs constituted part of the secondary data sources utilised. The FGDs were conducted when the authors were training ward and districtlevel disaster risk management committees.

\section{Research methodology matrix}

A matrix was drawn up, indicating the research methodology for the study (Table 2).

\section{Disaster experiences based on field research}

The frequency of responses that informed the study was analysed (Figure 1).

\section{Personal information of respondents}

In terms of the age composition of the sample, $43 \%$ were in the 18-30 year age group (Figure 2). Females made up 43\% of the total sample, whilst males constituted $57 \%$. Thirty-two percent of informants were in formal employment, whilst $46 \%$ were unemployed. Fourteen percent indicated that they were into informal employment. Fifty-four percent of the sample went up to secondary school level, whilst $27 \%$ indicated that they had gone up to tertiary level. Thirteen percent went only to primary school, whilst $1 \%$ never went to school. The majority of the sample therefore had the potential for a fairly good understanding of disaster, development and livelihood issues that the research sought to investigate.

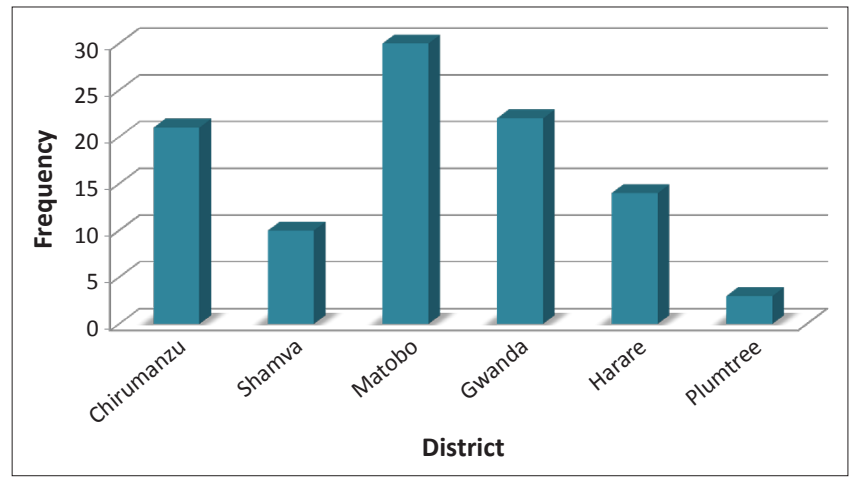

FIGURE 1: Frequency of responses.

TABLE 2: Research methodology matrix.

\begin{tabular}{|c|c|c|}
\hline Data collection tool/method & Justification & Data source \\
\hline $\begin{array}{l}\text { - Questionnaires - mixture of closed and } \\
\text { open-ended questions ( } 20 \text { closed questions } \\
\text { and } 6 \text { open) }\end{array}$ & $\begin{array}{l}\text { - To elicit responses from subjects that can be quantified and } \\
\text { comparable to derive key trends and patterns on disaster risk script } \\
\text { - Open-ended questions provide for flexibility in responses, thereby } \\
\text { accommodating diversity }\end{array}$ & $\begin{array}{l}\text { - Disaster Management students at NUST (mainly MSc } \\
\text { Disaster Management and Diploma in Disaster and } \\
\text { Development Management) } \\
\text { - DRR practitioners in NGOs } \\
\text { - Officers of relevant central and local government } \\
\text { departments }\end{array}$ \\
\hline $\begin{array}{l}\text { - Interviews - structured (key informant) } \\
\text { (applied to the } 6 \text { open-ended questions in } \\
\text { the questionnaire) }\end{array}$ & $\begin{array}{l}\text { - To allow for subjective and interpretive responses } \\
\text { - For cross-checking responses given to questionnaires and data } \\
\text { collected through observation }\end{array}$ & $\begin{array}{l}\text { - Community members disaggregated according to } \\
\text { gender, age group, vulnerability status (e.g. disabled) } \\
\text { - DRR lecturers from NUST } \\
\text { - DRR trainees from NGOs }\end{array}$ \\
\hline - Field visits or observation or transect walks & $\begin{array}{l}\text { - Capturing phenomena that cannot be captured by other methods, } \\
\text { for example mood, and other non-verbal cues } \\
\text { - Production of transect profile of study areas }\end{array}$ & $\begin{array}{l}\text { - Shamva District } \\
\text { - Gwanda District } \\
\text { - Matobo District } \\
\text { - Chirumanzu District } \\
\text { - } \text { Hamtree District } \\
\text { - Harare }\end{array}$ \\
\hline - DRR experts opinion & $\begin{array}{l}\text { - Proper usage of DRR jargon } \\
\text { - Taking into account new DRR models and changes to conventional } \\
\text { or common models and tools }\end{array}$ & $\begin{array}{l}\text { - } \text { DRR practitioners } \\
\text { - NUST Lecturers }\end{array}$ \\
\hline $\begin{array}{l}\text { - Secondary data review (DRR training reports, } \\
\text { curriculum, project progress reports) }\end{array}$ & $\begin{array}{l}\text { - Capturing historical trend of phenomena under investigation } \\
\text { - ComR education and training) } \\
\text { changes }\end{array}$ & $\begin{array}{l}\text { - DRR training modules or manuals or books } \\
\text { - DRR and development journals from the internet }\end{array}$ \\
\hline $\begin{array}{l}\text { - Content analysis (videos and posters on DRR } \\
\text { training or education) }\end{array}$ & $\begin{array}{l}\text { - Reliving and transcribing data that could not be captured at the time } \\
\text { of occurrence of events under investigation (training and education) }\end{array}$ & $\begin{array}{l}\text { - DFID-CHF DRR videos } \\
\text { - Field training videos }\end{array}$ \\
\hline
\end{tabular}

DRR, disaster risk reduction; NUST, National University of Science and Technology; NGO, non-governmental organisations; DFID-CHF, Department For International Development-Conflict and Humanitarian Fund. 


\section{Disaster risk experiences}

\section{Knowledge on disasters}

Under this section, respondents were asked to indicate how they gained knowledge on disasters (Figure 3). The

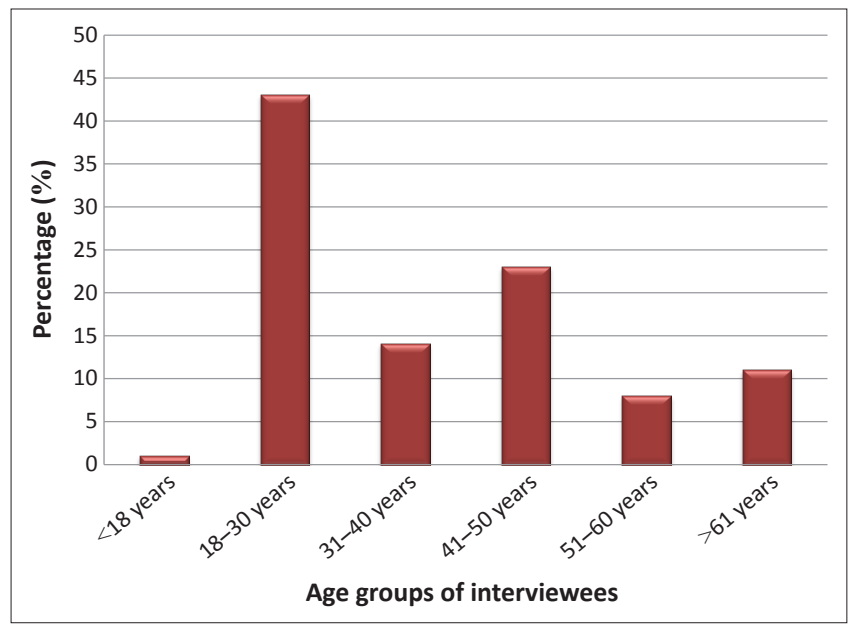

FIGURE 2: Age groups of interviewees. overall responses showed that 25\% knew about disasters through formal education, $13 \%$ through informal education, $12 \%$ through radio and $12 \%$ through television. Only $5 \%$ gained some knowledge on disasters through practically experiencing the disasters.

\section{Major disasters experienced}

Having established how people got to know about disasters, the next question focused on indicating the major kinds of disasters faced in their areas (Figure 4). Drought emerged as the most common, with $36 \%$ indicating it as a major disaster in their area. Fires came second at $6 \%$, whilst a combination of drought, fire, traffic accidents and human diseases had $11 \%$ of the sample indicating these were major disasters.

\section{Knowledge about impending disasters and their severity}

Since the research is on configuring and reading the disasters risk script, it was necessary to probe on how people got to know about impending disasters (Figure 5). In response to this, $22 \%$ indicated that they were informed by radio, $14 \%$ by television, $5 \%$ through formal education and $5 \%$ through

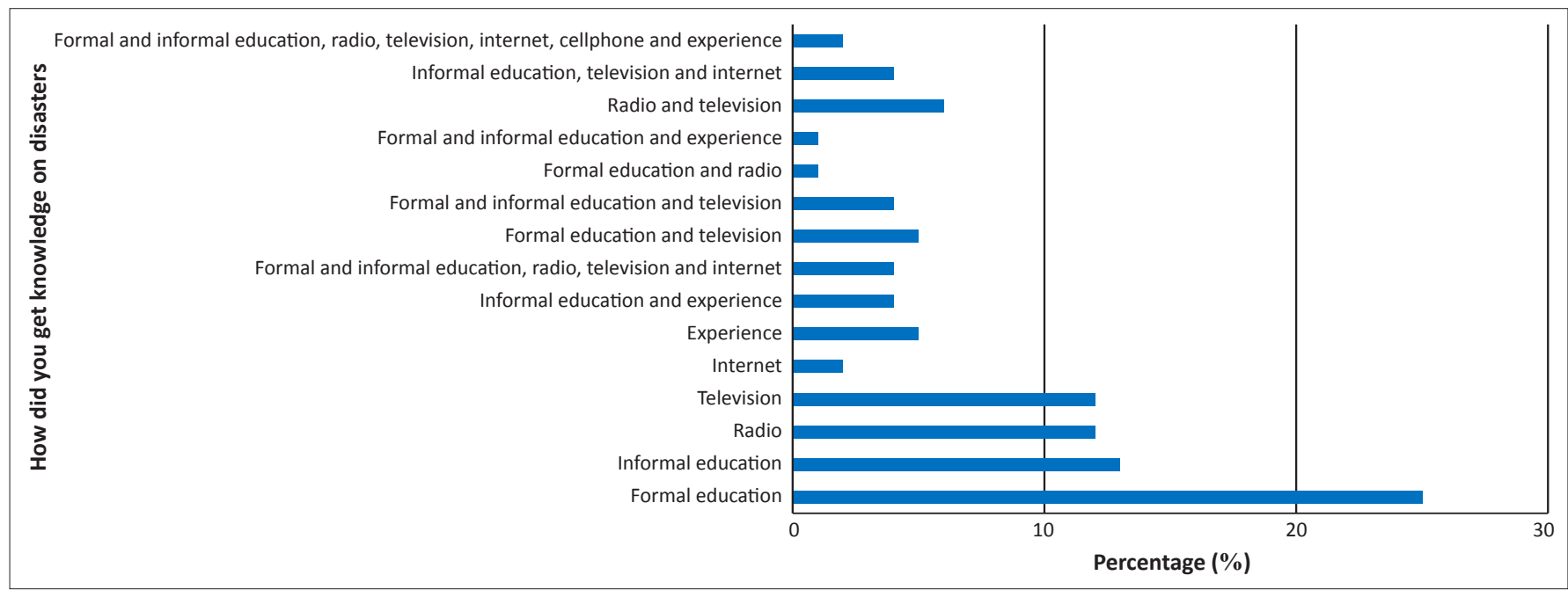

FIGURE 3: Acquisition of knowledge on disasters.

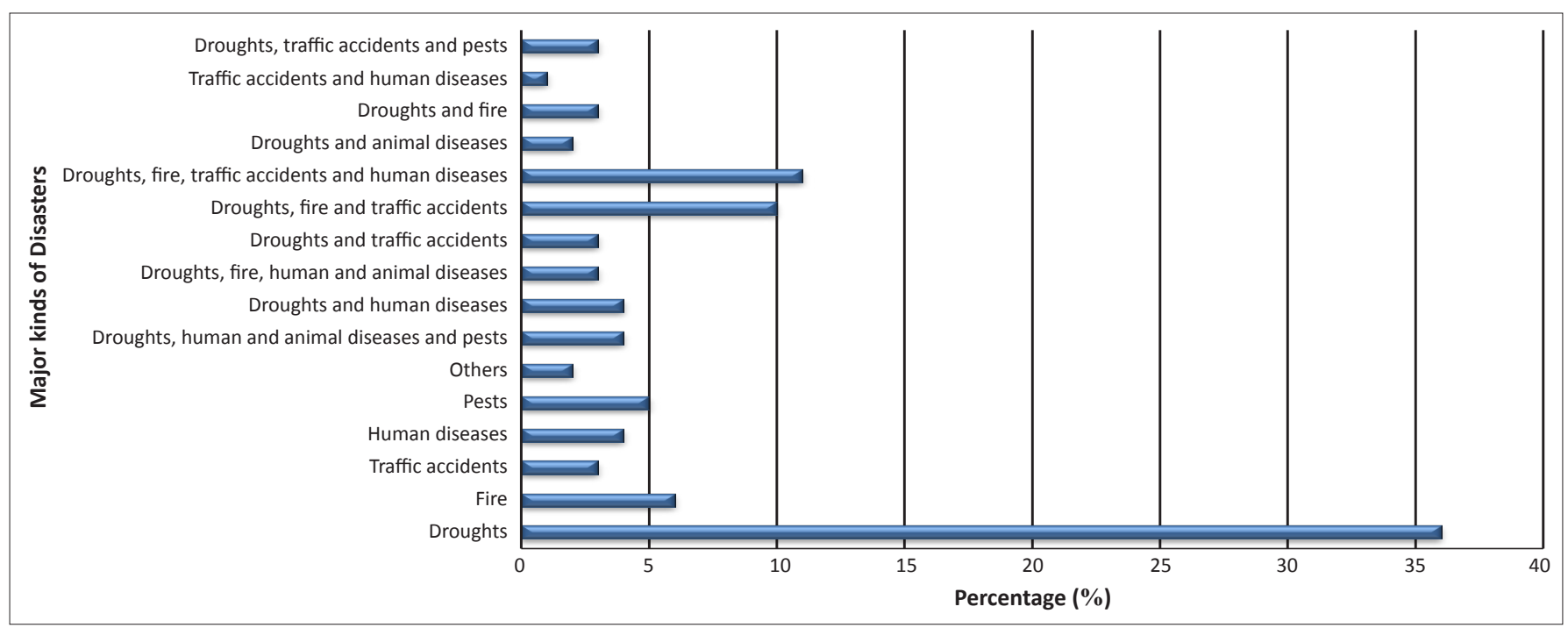

FIGURE 4: Major kinds of disasters. 
internet. Ten percent of the sample indicated that they got to know about impending disasters through a combination of radio and television. Respondents were then asked further to indicate how they determined the severity and impact of impending disasters (Figure 6). Roughly a quarter (24\%) indicated that they could tell from experience, 52\% from weather forecasts and 3\% from indigenous early warning systems (IEWS). Ten percent indicated that they could tell the severity of impending disaster based on a combination of experience and weather forecast, and $56 \%$ of respondents indicated that weather forecasts on radio, television and newspapers were what best informed their determination of the severity and impact of disasters that affected their areas.

\section{Early warning systems}

The next focus of inquiry was to ask respondents to indicate the Early warning systems (EWS) they were familiar with (Figure 7). Sixty-one percent said they were familiar with weather forecasting on radio, television and newspapers. Five percent indicated that they were using the internet as EWS, 2\% used cell phones and 2\% mentioned IEWS. Seven percent indicated a combination of internet and weather forecast. In terms of how accessible these EWS were, 57\% indicated that the accessibility ranged from good to excellent, $24 \%$ indicated that accessibility was neither good nor bad and $10 \%$ indicated that accessing these EWS ranged from

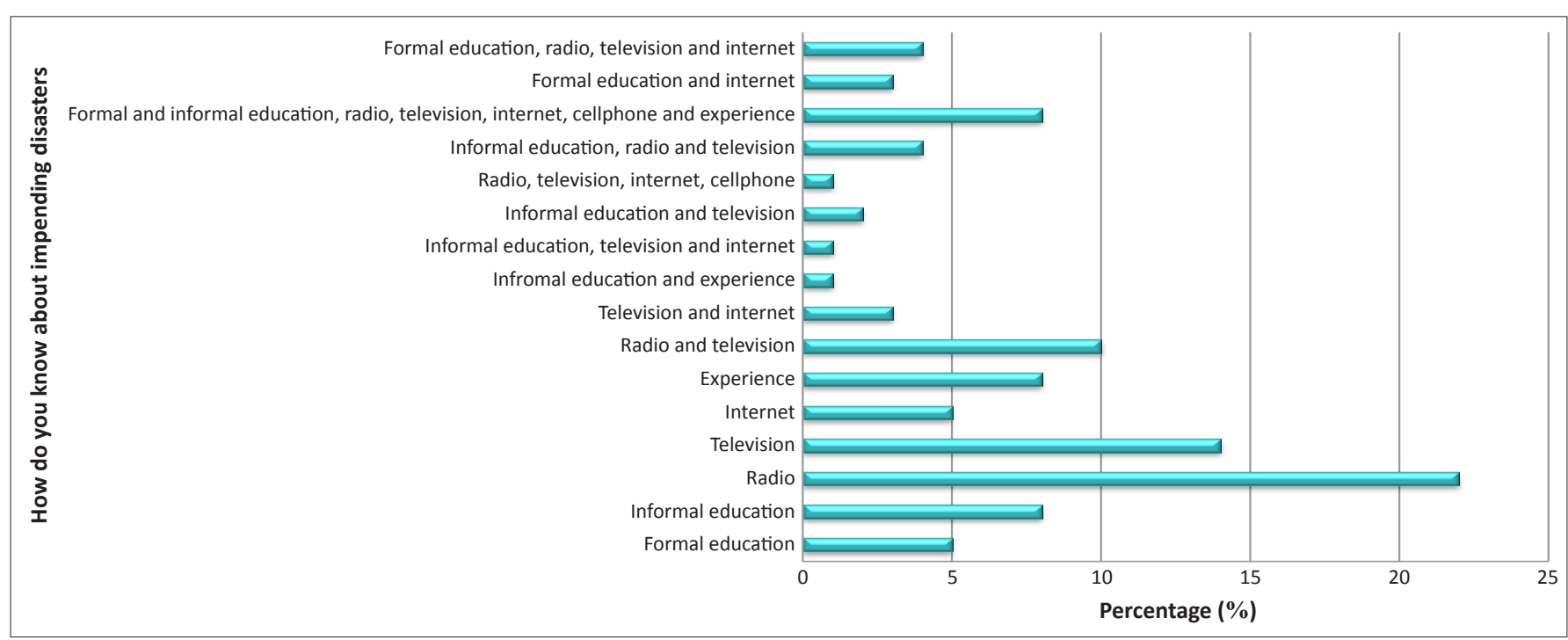

FIGURE 5: Knowledge of impending disasters.

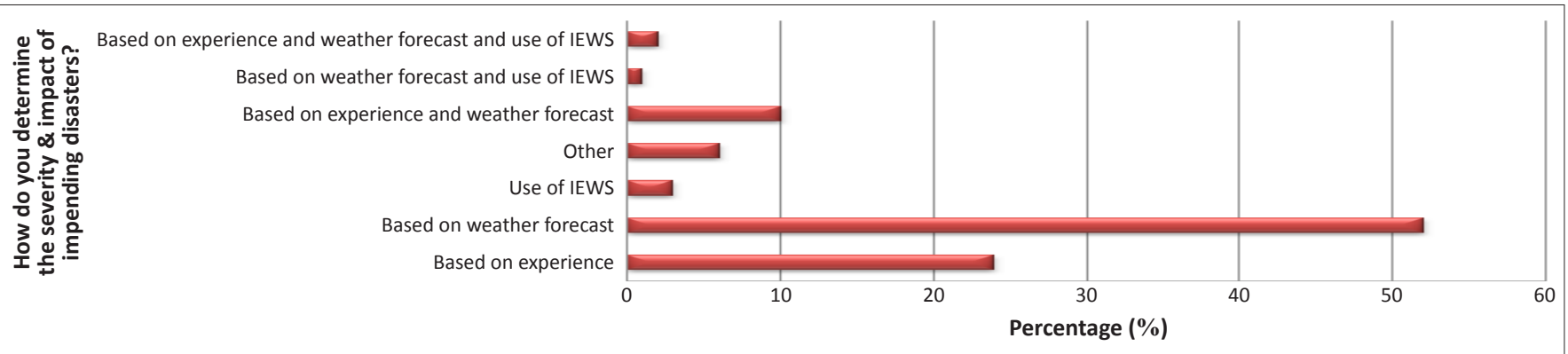

IEWS, indigenous early warning systems.

FIGURE 6: Determination of severity and impact of disasters.

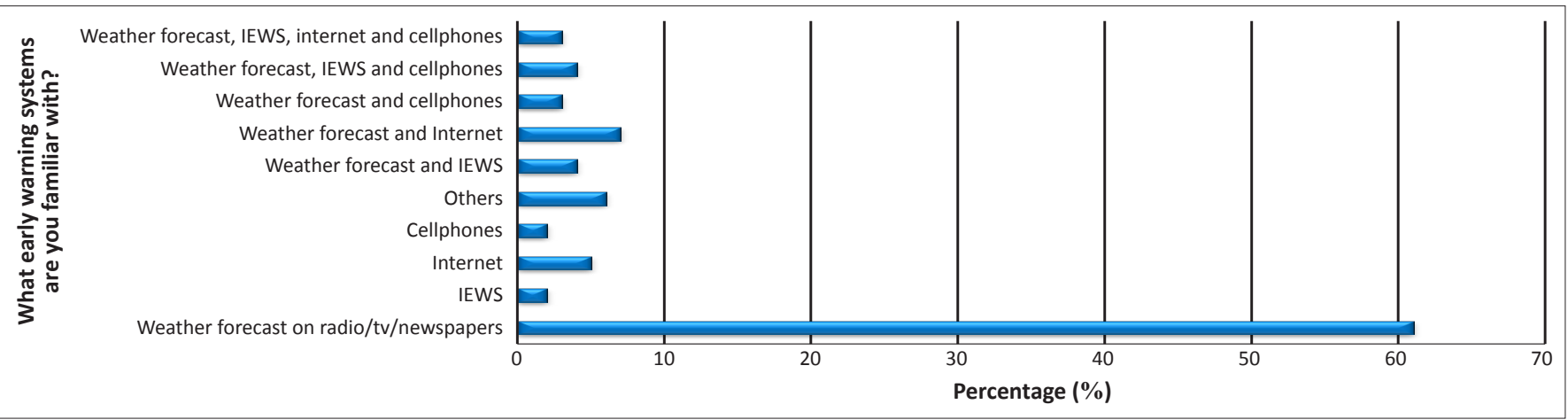

IEWS, indigenous early warning systems.

FIGURE 7: Early warning systems. 
bad to inaccessible. Asked to comment on the usefulness of these EWS to effective DRR, $55 \%$ of respondents indicated that they ranged from useful to very useful, $17 \%$ said they were 'somewhat' useful, and $15 \%$ were not sure.

\section{Livelihoods and disasters}

\section{Most useful livelihood strategies}

Respondents were next asked to indicate the most useful livelihood strategies for their households (Figure 8). Twentyseven percent said that rain-fed crop cultivation was their main livelihood, 19\% livestock rearing, 14\% vegetable production and $8 \%$ vending. On livelihood combinations, $10 \%$ indicated that they survived on vegetable production and rain-fed crop cultivation, whilst another $10 \%$ indicated that they survived on livestock rearing and rain-fed crop cultivation.

\section{Household support when faced with disaster-induced hardships}

When asked where they got support in times of disaster induced hardships, respondents came up with varying responses (Figure 8). Twenty-seven percent indicated that they got support from NGOs, $16 \%$ from the extended family, $11 \%$ from the government and $6 \%$ from the community. Nine percent indicated that they got support from a combination of the extended family, NGOs and Community Based Organisation (CBOs), and 6\% indicated a combination of extended family, government and NGOs.

\section{Personal action for dealing with disasters}

Respondents were asked to indicate what action they took to protect themselves and their assets from disasters. Twentythree percent indicated that they had undertaken croprelated activities, 16\% had undergone DRR training, 9\% were involved in practical DRR activities and 6\% were involved in livestock-related activities. Nine percent indicated that they made recourse to other activities apart from all the ones indicated above. After this, respondents were asked to rate their own ability to anticipate, cope with, and respond to disasters. Forty-one percent indicated an average ability to deal with disasters, $20 \%$ indicated good ability and $6 \%$ excellent ability. Twelve percent indicated that their ability to deal with disasters was bad.

As a follow up to the above section, respondents were asked to identify factors that affected their ability to respond to disasters should they occur. The most common factors identified were as follows:

- lack of resources (hampers coping and response capacity)

- poor communication about disasters (late warning)

- knowledge on disasters (uncertainty, resulting in working on assumptions)

- lack of capital

- age

- impairment (both physical and mental disability)

- lack of planning

- experience

- elders do not listen to young children

- lack of cooperation from other people

- lack of time to teach people on disasters

- not enough food for emergency relief

- will power

- politics may be a drawback, especially when mobilising people and educating them (words have to be selected wisely) and information about financial support may have to be censored

- interference from outside

- religious beliefs and differences

- political beliefs and differences.

\section{Hazard ranking}

Respondents were asked to rank seven hazards as they affected their livelihood, with one ranked as highest and seven as lowest. The hazards to be ranked were: drought, floods, HIV and AIDS, veld fires, crop pests and animal

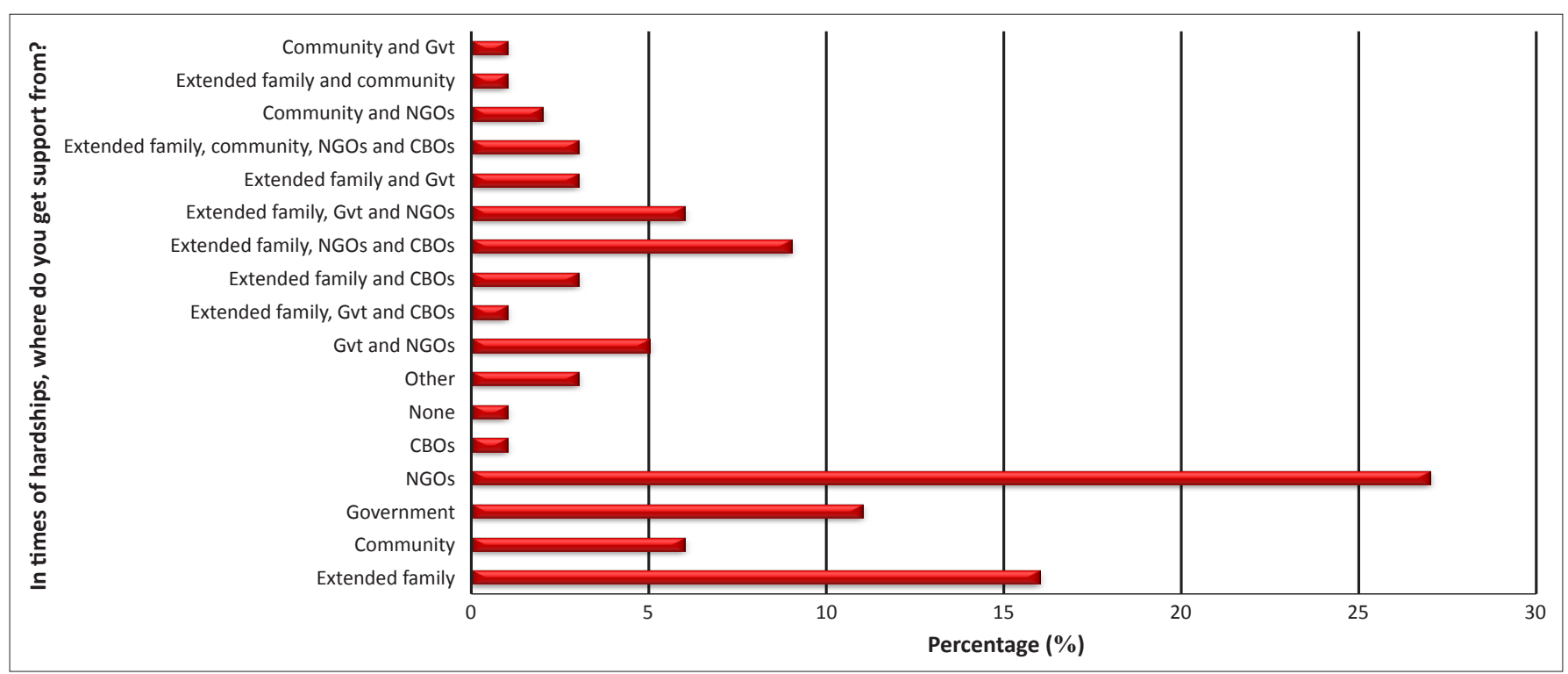

Gvt, government; NGO, non-governmental organisations; CBO, Community Based Organisation.

FIGURE 8: Support in times of disaster-induced hardships. 
diseases, traffic accidents and other human diseases (other than HIV and AIDS, which needed to be specified by each respondent). The research data yielded the following ranking, in descending order:

1. drought

2. HIV and AIDS

3. crop pests and animal diseases

4. traffic accidents

5. veld fires

6. floods

7. other human diseases.

\section{How do you view disasters or hazards in your community?}

Respondents were asked how they viewed the hazard or disaster trend in their communities in three phases as follows: 5 years ago, presently and in 5 years to come. Overall, the less literate people viewed disasters as getting worse with time. They had a more fatalistic attitude, some of it seen in their emphasising the fact that most disasters were a result of people abandoning their culture and even in some cases being so sinful to have incited the wrath of the gods and God. In this viewpoint, disasters were being seen as punishment for some transgression. In contrast, the more literate respondents indicated that even though hazard events are increasing, people will be able to address them as there was an increase in DRR training and awareness-raising. They acknowledged the role played by climate change in complicating the entire hazard-disaster-livelihood scenario. One interesting pattern emerging from the responses is the attempt made by many respondents to link disasters to the state of the economy. There were indications from some that the socio-economic challenges the country went through between 2002 and 2009 made the coping capacity of people very low, thereby magnifying disasters (which in actual fact were hazards, but the use of the word 'disasters' by the general public instead of hazards was well understood).

In relation to this, one male respondent had this to say:

'When people do not have resources, anything can develop into a disaster ... For the past five years the economy was bad and we saw lots of disasters - cholera, drought, floods, and many people died ... Presently [July 2012], although the environment has not changed, most people have resources and are coping well.' (Male, in his 40s, from Chirumanzu District)

\section{What factors determine your perception of disaster risks that affect your area?}

Respondents were asked to identify factors that determined their perception of disaster risks that affect their area. It was explained to them that they were required to identify factors that influenced how they understood and interpreted the severity of the risk of a particular disaster. The following were the major factors identified by respondents:

- culture, belief systems and the way disasters are communicated

- experience with disasters or hazards. On this, a man from Chirumanzu had this to say: 'Experience has taught us a lot. The heat from the sun tells you much about lightning, floods and droughts. So when you see certain signs you know in advance the severity of a disaster' (male, from Chirumanzu).

- knowledge

- weather conditions

- improper understanding and interpretation of English terms used in disaster education

- following what others are doing

- listening to the elders

- access to radio and television

- bad reputation of weather reports due to inaccuracies, so people tend not to believe them

- lack of understanding of some of the information disseminated through the various media platforms due to the jargon used

- the manner in which the disaster affects an individual determines whether they see a disaster as severe or not.

- the number of old people and children in the area together with households headed by women and children

- the poverty level of the people

- alternative livelihood strategies available

- extended family status and cooperation

- the level of availability of the 'commons' and people's accessibility to resources, for example boreholes

- previous year's harvests.

\section{How to improve on ability to anticipate, cope with, and respond to disasters}

When respondents were asked to explain how they thought they could improve on their ability to anticipate, cope with, and respond to disasters, they came up with the following answers:

- improving (disaster risk) communication system (timeliness and accuracy)

- disaster and early warning education (short courses on how to cope with disasters). This also includes inclusion of DRR in the school curriculum.

- sourcing donors (need help from other people)

- safer agricultural and livelihood practices like early ploughing, food preservation

- provision of infrastructure that strengthens resilience, for example irrigation facilities, electricity, need to improve radio and television reception

- improved coordination by leadership, and having the support of elders and people who dominate top positions in the community

- efficient response teams, from health personnel to fire brigade

- use of indigenous knowledge

- developing information-sharing networks and promoting linkages with both local and regional disaster management bodies

- campaign for increased concern for environmental issues.

\section{Discussion of research findings on disaster risk script experiences}

Having presented the key findings from the field, this section attempts to explain them in relation to past research findings and the existing body of knowledge. There has been reference 
to the 'disaster as spectacle' phenomenon, which emanates from the fact that in the modern world the meaning of disaster cannot easily be dissociated from how it is portrayed and interpreted by the mass media (Couch 2000):

In the popular culture shaped by and reflected in the media, news is essentially whatever people are interested in. Newsworthiness is defined by people's interest levels. Disaster assumes a symbolic value as a spectacle, as a story or saga, or as competition, imbued with notions of the breakdown of society, the spread of anarchy, heroic leadership and villainous malevolence. (Alexander 2005:33)

This can be related to why some of the people interviewed did not consider some issues as disasters in some instances, with this characterisation changing over time and context. In some cases, as some of the respondents put it, the media have played a big role in portraying disasters. This applies to large-scale catastrophes that make international headlines, for instance the Japanese tsunami of 2011, or the 'Arab Spring' of 2011, particularly in Egypt and Syria.

Many traditional societies still face up to the scourge of disaster with religiously-inspired fatalism (Sims \& Baumann 1972). Catastrophe is once again an 'Act of God', a punishment for sins committed, part of an inscrutable higher plan. Are we to call this retrograde, a sign of cultural underdevelopment? Such means of rationalising disaster are coping mechanisms and we might judge whether or not they are effective ones. Certainly the symbolism involved is no worse than that constructed by the western media (Vitaliano 1973, frontispiece). In Gwanda, for instance, there was general talk about red cloths and dry bones in the bush and their relationship to disasters, which seems to be embedded in religious beliefs and cultural practices. In fact, it was striking to note that in responding to the question on belief systems and their relationship to disasters, most people interviewed referred to IEWS. One of the respondents from Gwanda, had this to say:

'People believe that if the bush is full of dry bones and red garments no rain is going to fall or a little rain, unless they pick them [up] and burn [them].' (Female, teenager, from Gwana)

Perhaps one reason why 'disaster' will probably never be completely, immutably defined is because the definition depends on shifting portrayals and perceptions of what is significant about the phenomenon. We would argue, as observed by other authors, that disaster must be interpreted, and continually reinterpreted in the context of contemporary issues (Alexander 2005:37). In relation to this, some respondents mentioned the way the 2008 cholera outbreak in Zimbabwe was interpreted and managed. From the analysis, it was clear that Zimbabwe had always experienced episodes of cholera, but the 2008 one was amplified by the socio-economic meltdown that the country was going through. Goffman (1974:21) uses the term 'frame' to denote 'schemata of interpretation that enable individuals to locate, perceive, and label that which happens in their life space and the world at large'. Such frames organise experience and guide action by rendering particular events as meaningful. In this research, such frames were visible and distinct. For instance in Gwanda and Matobo, which are predominantly semi-arid and arid, and where livestock rearing is practiced relatively more widely than in Shamva and Chirumanzu, disasters had more to do with livestock. In contrast, in Shamva and Chirumanzu, relatively wetter parts of the country, the disaster frame had to do with rain-fed crop cultivation, lending credence to the above assertion by Goffman.

As Anderson (2011) argues, not all cultural responses are equal, however, and disasters result in fierce competition over which interpretations hold sway over the collective imagination and, more to the point, the political establishment. This process of negotiation dictates how a society responds to disaster as a whole, usually via political mediation, and it leads to cultural change as the experience of disaster is integrated into a society's world-view through normalising mechanisms. A case in point is the cholera outbreak in Zimbabwe alluded to earlier on. As the epidemic broke out, the Zimbabwean public, the international community and many other players in development were inundated with multiple viewpoints and opinions on its cause, and how best to reduce its impact. In the midst of such knowledge generation, there were constellations and coalitions around certain points of view on the epidemic, in ways that tended to entrench polarisation in a country already riddled with political tension. Whereas the government attempted to put in place emergency multi-sector response mechanisms largely led by UNICEF, there were accusations that government was not doing enough to protect lives. One key feature of this era was the trading of accusations and counteraccusations between the Zimbabwe government and human rights groups, including media organisations on the actual cause of the outbreak and the way forward. On the one hand, the authorities in Harare labelled the outbreak as a deliberate creation of Western powers who wanted to create an impression that the country was in a state of anarchy and that government had failed to protect its citizens. By coincidence, the cholera outbreak originated from Budiriro high density suburb, an area known to be an opposition party stronghold. Following from this, it was therefore said that government had deliberately created the outbreak as a way of punishing and if possible, eliminating opposition supporters. Theorists from Gramsci to Foucault have demonstrated that discourse never exists outside ideology. Even when disasters are not mediated by formal literary or cultural production, the process of narrating the disaster mobilises existing social and political power relations at the same time that it renegotiates them (Kirschenbaum 2004).

We have seen from the field data that only $5 \%$ of respondents reported having gained disaster knowledge through experience, and $4 \%$ reported having gained disaster knowledge through a combination of informal education and experience. The data have also indicated that when asked to rate their ability to respond to disasters should they occur, $41 \%$ of respondents said they had average ability, $12 \%$ rated their ability as bad, whilst $2 \%$ rated themselves as very bad. Only 26\% rated themselves as having good and excellent ability. This high rate of people not being confident of their ability to respond to disasters could be explained by the low rate of practical experience with disasters. This corroborates research by other scholars. Growing empirical research 
suggests that both perceptions of risk and preventative behaviour are influenced by the emotions of past experiences (see Slovic et al., in Siegrist \& Gutscher 2008:772). Fear is an emotion pertinent to the experience of disasters. Fear is incredibly powerful and has been shown to influence people's behaviour and attitudes to disaster preparedness. Siegrist and Gutscher (2008:777) found, for example, that '... people with flood experience stated more often that fear of flood damage was an important factor in implementing preventative measures'. Similarly it is fear of looting that has been identified as deterring people from evacuating in the event of technological disasters (Perry 1985, in Raid, Norris \& Ruback 1999).

Cultures form through the process of adaption to distinct environments; 'cultures of disaster' form when frequently occurring natural hazards are integrated into the schemata of daily life. This has arguably been lacking in most parts of Zimbabwe, where disasters have not been that frequent. At least in Matobo and Gwanda, by exception, one could talk of 'cultures of drought', as a result of the long history of almost perennial droughts that afflict these semi-arid districts of Matabeleland South province. In general terms, there is probably scope to talk about a 'culture of HIV and AIDS disaster' in Zimbabwe. This, however, is also subject to localised negotiation of meanings with regard to what a particular community considers to be a disaster stage of HIV and AIDS. In fact, there have been instances in development programming where some people who tested negative to HIV would be despondent over the loss of free food handouts and other forms of support that people living with HIV and AIDS and their families received from donors. To corroborate this, Alexander (2005) argues that characteristics termed vulnerable depend on the point of view adopted. For instance, Russia has been saved at least three times from invading armies because the winter was a significant factor in their enemies' defeat. Storms were a key factor in at least two English naval victories. In these cases, one side saw weather damage as vulnerability whilst the other side saw the weather damage as being helpful. The label depends on to whom the damage was being done and the point of view adopted.

We have seen that for most respondents in this study, lack of understanding of some of the information disseminated through the various media platforms due to the jargon used was one of the major factors they indicated as crucial in their determination of perception of disaster risks that affect their area. Closely related to this is the issue of improper understanding and interpretation of English terms used in disaster education, where people are still grappling with the most appropriate vernacular terms for key concepts. Some of these terms include hazard, risk, vulnerability and adaptation. In relation to this, Twigg and Steiner (2002) assert:

Zimbabwean NGOs are also uncomfortable with the terms 'preparedness' and 'mitigation', and, since drought is the main natural hazard they are addressing, are more likely to adopt terms used in food security and natural resource management. (p. 477)
The difficulty in clarifying terms and concepts may be partly due to the fact that many have no equivalent in local languages. Elsewhere there is a tendency to re-label other types of work ('relief' or 'rehabilitation' in Bangladesh, 'development' in Nicaragua) as 'mitigation' or 'preparedness', showing that there has been little or no thinking about what these concepts mean (Twigg \& Steiner 2002:477). It may be time to discard the old terminology and adopt the more accessible language of 'risk' and 'risk reduction', which is already in common use and more readily understood.

Mention has been made of respondents who indicated that they first consider how a disaster might affect them as individuals or as individual households and this determines their perception of its severity for the wider community. By implication, as long as these people consider themselves 'safe', then they are less likely to worry about what happens to the next person, in a manner indicative of 'off-loading' the disaster risk onto someone else. As Paton, Smith, Daly and Johnston explain in their study (2008):

... in doing so, people transfer risk to others within their community rather than accepting this risk themselves. If all members are making similarly biased assumptions about the distribution of risk within a community, no change in either the level of perceived risk or their level of preparedness is likely to occur. (p. 182)

Individuals not only transferred risk to other members of their community, but also to agencies responsible for disaster risk management (DRM) (Paton et al. 2008). Ironically, but also somewhat worryingly, the more campaigns there were about safety, the less people felt they needed to act. This finding has been termed 'risk compensation' (Paton et al. 2008:182). This kind of behaviour has also been observed with regard to HIV and AIDS risk perception.

We have observed that disaster scenario postulation has been related to the level of literacy of respondents. We saw that the more literate, even though acknowledging the increase in frequency of hazards and disasters, envision the future as composed of society that is more disaster resilient as a result of widespread DRR training and awareness-raising initiatives. For the less literate, the opposite is true. Income and education do seem to place limits on what people are able to do in response to the level of risk they perceive. Sakallı (2000), reporting on a Turkish sample of people affected by an earthquake, brings in the income factor, stating that people may be unable to put their positive intentions into practice because of expenses. Farley (1998) reports on a phenomenon of rational preparedness and irrational response, namely that what people say they will do is not borne out by their actions. This is a key statement, that claims about intention to mitigate and actual completed mitigation do not necessarily match (Fisek et al. 2002:12). Altogether these results indicate that no matter what their risk assessment, or attitude, people have to perceive an element of feasibility, financial or otherwise before they engage in actual mitigation. Clearly, an effective educational campaign has to provide not only information on how to prepare for disasters, but also information on the demonstrated effectiveness of each kind of preventive effort (Fisek et al. 2002:12). 
In the authors' interactions with a number of professionals in Zimbabwe, these learned people have drawn us into debating whether Zimbabwe has problems of disasters, and if so, which ones. In one job interview that I (Bongo) attended in April 2012, one learned professor in the panel was also resolute in his assertion that we needed not be worrying about disasters in Zimbabwe, as they were phenomena affecting other parts of the world and not us. Placing this into the context at hand, one can state that disasters are what communities define as disasters, and are thus the outcome of social constructions.

\section{Conclusion}

As we try to work towards safer and disaster-resilient communities, there is need to pay attention to symbols and underlying culture and history to provide insight for designing systems that can support people in certain cultures to rebuild their lives and to prepare for future disasters, (Wilensky 2011). There is also need to emphasise the importance of understanding national and regional culture and the history and characteristics of people who are affected by disasters. These factors should be well considered for design of future systems which are used in various stages of disasters, ranging from rescue and clean-up phases to disaster preparedness and long-term recovery planning (Wilensky 2011).

Clearly coming out of this research is the central role played by experience in informing the reading and interpretation of the risk script. Research on flooding in Switzerland could provide us with some insights on this. The findings showed that people who experience flooding are more likely to take preventative action against future risks because of their ability to remember negative emotions associated with the experience. The implication for DRM strategies is that: 'The challenge of risk communication lies not so much in providing rational information but in adequately addressing the experiential system' (Siegrist \& Gutscher 2008:777). Siegrist and Gutscher (2008:771) suggest that risk reduction must move beyond a focus on the technical aspects of flooding to include triggers for motivating mitigation behaviour, which in this case are the negative emotional consequences of natural disasters. This poses a challenging question for disaster risk managers: 'Can there be a substitute for direct, personal experience?' (Siegrist \& Gutscher 2008:777).

The use of the term 'bounded rationality' is useful here, when applied to the DRM sector. Schipper and Dekens (2009:1) explain that '... people have bounded rationality; that is, people's rationality is limited to their own information, beliefs and (economic) tradeoffs'. This term is useful for thinking not only about the role of culture in determining communities' choices, behaviour and preferences, as Schipper and Dekens (2009) use the term, but in turning a critical lens to the DRM sector: we employ our own bounded rationality when seeking to enact DRM interventions, which often do not align with the rationality of the people we are trying to help.

As we digest the issue of interpreting and reading the disaster risk script, we might want to consider taking a cue from an old Chinese tale about an Emperor who one day asked his court artist, 'What is easy to paint and what is difficult to paint?' The courtier thought hard on this for as long as he knew his master's tolerance would permit and replied, 'Dogs are difficult, but demons are easy'. The courtier explained further to his Emperor that obvious things are hard to get right because everyone knows all about them and hence everyone thinks they know what the essence of a dog is. However, since no one has actually seen a demon, drawing one is easy because who can say it is not correct (Britton 2005:113). Is disaster a dog, because when one occurs it is 'obvious', or is it a demon, because, up to now at least, no-one really knows what it is? Even though both scientist and citizen have trouble reaching agreement about what the precise factors are, it seems that most are certain when a disaster has occurred. The Chinese story therefore underlines the importance of subjective experience and contextual factors in interpreting the disaster risk script.

\section{Acknowledgements Competing interests}

The authors declare that they have no financial or personal relationship(s) that may have inappropriately influenced them in writing this article.

\section{Authors' contributions}

P.P.B. (National University of Science and Technology) was the project leader in documentation and development of research instruments; P.C. (National University of Science and Technology) was the team leader of the Disaster Risk Reduction Unit at National University of Science and Technology, and also responsible for development of research instruments; M.S. (National University of Science and Technology) and F.M. (National University of Science and Technology) were responsible for leading the fieldwork and brainstorming on key thematic issues.

\section{References}

Adger, W.N. \& Brooks, N., 2003, 'Does global environmental change cause vulnerability todisaster?', in M. Pelling (ed.), Natural disasters and development in a globalizing world, pp. 19-42, Routledge, London.

Alexander, D., 2006, 'Globalization of disaster: Trends, problems and dilemmas', Journal of International Affairs 59(2), 1-22.

Alexander, D.E., 2005, 'An interpretation of disaster in terms of changes in culture, society and international relations', in R.W. Perry \& E.L. Quarantelli (eds.), What is a disaster? New answers to old questions: International Research Committee on Disasters, pp. 1-15, Xlibris Press, Philadelphia.

Anderson, M.D., 2011, Disaster writing: The cultural politics of catastrophe in Latin America, University of Virginia Press, Charlottesville and London.

Barton, A.H., 2005, 'Disaster and collective stress', in R.W. Perry \& E.L. Quarantelli (eds.), What is a disaster? New answers to old questions: International Research Committee on Disasters, pp. 125-152, Xlibris Press, Philadelphia. PMid:15637677

Boehm, D.B., 1997, Risk communication in southern California: Ethnic and gender response to 1995 revised, upgraded earthquake possibilities. Quick Response Report \#94, viewed 21 July 2012, from http.www.colorado.edu/hazards/index.html

Britton, N.R., 2005, 'What's a word? Opening up the debate', in R.W. Perry \& E.L. Quarantelli (eds.), What is a disaster? New answers to old questions: International Research Committee on Disasters, pp. 60-78, Xlibris Press, Philadelphia.

Couch, S.R., 2000, 'The cultural scene of disasters: Conceptualizing the field of disasters and popular culture', International Journal of Mass Emergencies and Disasters 18(1), 21-38.

Dilley, M., Chen, R.S., Deichmann, U., Lerner-Lam, A.L., Arnold, M., Agwe, J. et al., 2005, Natural disaster hotspots: A global risk analysis, World Bank, Washington, DC. http://dx.doi.org/10.1596/0-8213-5930-4 
Farley, J.E., 1998, Earthquake fears, predictions, and preparations in mid-America, Southern Illinois University Press, Illinois.

Fisek, G.O., Yeniseri, N., Muderrisoglu, S. \& Ozkarar, G., 2002, 'Risk perception and attitudes towards mitigation', IIASA-DPRI Meeting Integrated Disaster Risk Management: Megacity Vulnerability and Resilience, Laxenburg, Austria, 29-31 July 2002.

Furedi, F., 2007, 'The changing meaning of disaster', Area 39(4), 482-489. http://dx.doi. org/10.1111/j.1475-4762.2007.00764.x

Goffman, E., 1974, Frame analysis, Harvard University Press, Cambridge, MA.

Jonsson, M. \& Sapir, D.G., 2009, 'Trends of Health Indicators in Zimbabwe', CE-DAT Technical Brief; CRED Working Paper no. 247, CRED, Brussels.

Kelman, I., 2011, 'Understanding vulnerability to understand disasters', in B.L. Murphy \& D. Etkin (eds.), Canadian disaster management textbook, n.p., Canadian Risk and Hazards Network, Toronto.

Kirschenbaum, A., 2004, Chaos, Organization, and Disaster Management, Marcel Dekker, New York.

Kuwait News Agency (KUNA), 2011, 'Ignoring 2011 disasters stats "unwise" step', UN Report, 19 January 2012, Online News Bulletin, viewed 05 August 2012, from http:// www.kuna.net.kw/ArticleDetails.aspx?id=2215778\&language $=$ en

Paton, D., Smith, L., Daly, M. \& Johnston, D., 2008, 'Risk perception and volcanic hazard mitigation: Individual and social perspectives', Journal of Volcanology and Geotherma Research 172, 179-188. http://dx.doi.org/10.1016/j.jvolgeores.2007.12.026
Raid, J., Norris, F. \& Ruback, B., 1999, 'Predicting evacuation in two major disasters: Risk perception, social influence, andaccess to resources', Journal of Applied Socia Psychology 29(5), 918-934. http://dx.doi.org/10.1111/j.1559-1816.1999.tb00132.x

Sakallı, N., 2000, How to change people's attitudes toward preparedness to earthquake: The application of the model of planned action, Paper presented at the Fifteenth Congress of Cross-cultural Psychology, Pultusk, Poland, July 16-21.

Schipper, L. \& Dekens, J., 2009, 'Understanding the roleof culture in determining risk from natural hazards', IOPConference Series: Earth and Environmental Science 6, $1-2$.

Siegrist, M. \& Gutscher, H., 2008, 'Natural hazards andmotivation for mitigation behaviour: People cannot predictthe affect evoked by a severe flood', Journal of Applied Psychology 28(3), 771-778.

Sims, J.H. \& Baumann, D., 1972, 'The tornado threat: Coping styles of North and South', Science 176(4042), 1386-1392. http://dx.doi.org/10.1126/science.176.4042.1386, PMid:17834637

Twigg, J. \& Steiner, D., 2002, 'Mainstreaming disaster mitigation: Challenges to organisational learning in NGOs', Development in Practice 12(3 \& 4), 473-479. http://dx.doi.org/10.1080/0961450220149807

Vitaliano, D.B., 1973, Legends of the earth: Their geologic origins, IndianaUniversity Press, Bloomington.

Wilensky, H., 2011, 'Disaster symbols and cultural responses', CSCW March, 19-23. 